\title{
Radiopharmaceuticals Production and Research Center at Heavy Ion Laboratory of University of Warsaw
}

\author{
J. Choiński*, K. Kilian, P.J. Napiorkowski, M. Pęgier, \\ A. Sentkowska, A. Stolarz and A. Trzcińska \\ Heavy Ion Laboratory, University of Warsaw, Warsaw, Poland
}

Doi: 10.12693/APhysPolA.139.413

*e-mail: jch@slcj.uw.edu.pl

\begin{abstract}
For over twenty years there has been a constant trend for scientific research to be applied in everyday life and thus raise the standard of living and improve the quality of life of ordinary citizens. Since the beginning of the 21st century, the Heavy Ion Laboratory, in cooperation with the Nuclear Medicine Department of the Independent Public Central Clinical Hospital of the Warsaw Medical University at Banacha Street, has undertaken joint actions to introduce in Poland the diagnostic tests commonly known as positron emission tomography scans. This article presents a brief history of the establishment of the Radiopharmaceuticals Production and Research Center together with its equipment and research work.
\end{abstract}

topics: radioisotopes, radiopharmaceuticals, cyclotron, FDG

\section{Introduction}

Following the prevailing trend to make scientific research applicable in everyday life and thus improve the standard of living and quality of life of ordinary citizens, the Heavy Ion Laboratory (HIL), in cooperation with the Nuclear Medicine Department of the Independent Public Central Clinical Hospital of the Warsaw Medical University at Banacha Street, has undertaken joint actions to introduce diagnostic tests in Poland utilizing a dedicated scanner using positron radiation (such medical tests are commonly known as PET scans). A scanner was installed at the hospital and production of the radiopharmaceutical known as fluorodeoxyglucose $\left(\left[{ }^{18} \mathrm{~F}\right]-\mathrm{FDG}\right)$, an essential requirement of the scanning procedure, was begun at the HIL in a specially designed facility — the Radiopharmaceuticals Research and Production Center (RPRC).

\section{Presentation of RPRC}

The center was built and equipped with subsidies from the Ministry of Science and Higher Education, the International Energy Atomic Agency, the Ministry of Health and the European Structure Funds within the Sectoral Operational Programme "Improvement of the Competitiveness of Enterprises" and the Operational Programme - Innovative Economy "Centre for Preclinical Research and Technology." The adaptation of the rooms and equipment was carried out by GE Medical Systems after winning a public tender. The RPRC has operated as a radiopharmaceuticals factory since March 22, 2012 and meets all the required conditions, including, of course, GMP [1]. The accelerator used in the center for the production of radioisotopes is a dual-beam (proton-deuteron) PETtrace 840 cyclotron manufactured by General Electric and the main production line is the dedicated $\left[{ }^{18} \mathrm{~F}\right]-\mathrm{FDG}$ line. There are also radiopharmaceutical production lines for radioisotopes, such as ${ }^{11} \mathrm{C}$ and ${ }^{15} \mathrm{O}[2]$ (see Fig. 1).

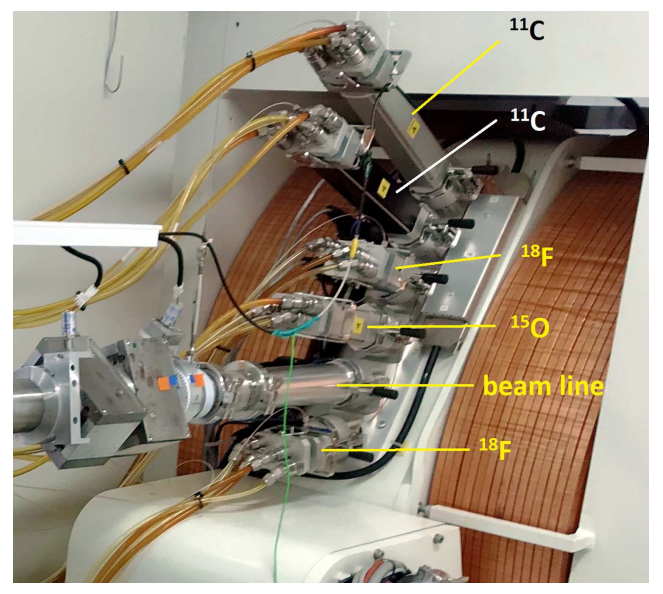

Fig. 1. Available targets and beam lines attached to the exit ports of the cyclotron. 
The site has three divisions: the cyclotron, a "Hot" Chemistry Laboratory and a Quality Control Laboratory. The cyclotron division consists of a cyclotron vault and a cyclotron technical room where all power supplies, the RF generator and heat exchanger are located. The existing area allows inter alia of regular maintenance of PIG ion sources and targets to be carried out. The "Hot" Chemistry Laboratory is divided into two laboratories. One, the so-called laboratory L1, is designed and equipped exclusively for FDG daily production. It contains: a laminar flow hood, double vertical hot cell, cell for a dispenser unit, two TRACERlab $\mathrm{MX}_{\mathrm{FDG}}$ synthesizers and DDS-VIALS dispenser.

Space is also available for upgrading and development of the equipment when the present production capability for FDG becomes insufficient. The available space will allow the installation of a double vertical hot cell with FDG synthesizer units and hot cell with dispenser unit (the first version) or two double vertical hot cells with four FDG synthesizers (the second version).

The daily production of FDG has been transferred to a dedicated, commercial company. Research activity remains the domain of HIL and we occupy a second laboratory, the so-called L2, which is designed and equipped for R\&D activity. In this laboratory, a laminar flow hood and four hot cells are installed. Two of them are double vertical and the other two are singles. Presently, L2 is equipped for the production of radiopharmaceuticals including ${ }^{11} \mathrm{C},{ }^{15} \mathrm{O}$ and ${ }^{18} \mathrm{~F}$, respectively. The equipment of L2 also allows for FDG production after fulfilling the necessary rules. It is assumed that L2 will be able to be used as an FDG production laboratory in the case of a temporary breach of GMP rules by the L1 equipment. The L2 laboratory is equipped with (i) water ${ }^{15} \mathrm{O}$ unit, (ii) ${ }^{11} \mathrm{C}$ "process unit", (iii) three units of ${ }^{11} \mathrm{C}$ synthesizers, i.e., -SynthraMeI, -SynthraMeIplus, -SynthraGPextent, (iv) dispenser unit, and (v) TRACERLab FX F-N for nucleophilic substitution with ${ }^{18} \mathrm{~F}^{-}$.

The Division of Quality Control Laboratory has two rooms. One is devoted to the instrumentation required by the European Pharmacopeia for FDG production, and instrumentation useful for $R \& D$ work is stored in the second.

\section{Research}

For several years, thanks to the implementation of grants, the cyclotron has been equipped with an external station for irradiation of solid state targets (metallic or powder). Such an extension of the setup significantly expanded the production and research capabilities of RPRC. This target station is attached via a beam line to the cyclotron, port No. 2. It is protected by Polish Patent No. 227402 (see Fig. 2).

The beam line consists of: a drift tube $(3.4 \mathrm{~m})$, two sets of steering magnets made of permanent

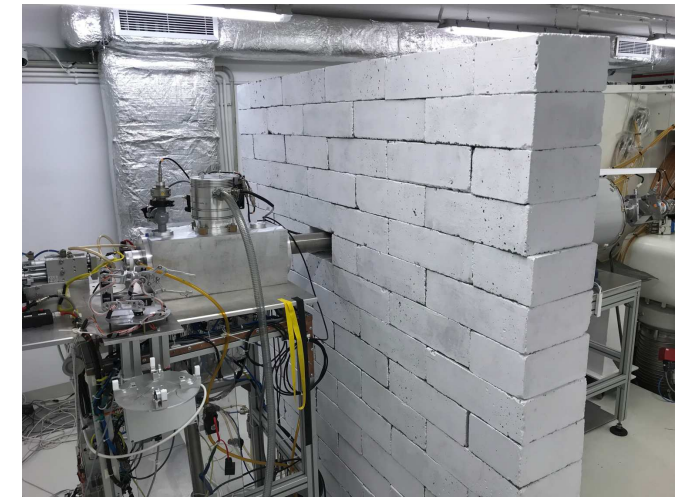

Fig. 2. Current view of the target system with beam line and radiation protection wall.

magnets, a quadrupole doublet and a four-sector collimator. The standalone external target system is shielded by a concrete wall of thickness of $0.25 \mathrm{~m}$. This protective wall ensures the safety conditions for the center staff. The beam line and the target station are connected to their own autonomous vacuum system which allows a static vacuum of $4 \times 10^{-7}$ mbar to be reached. The beam transport efficiency to the target is greater than $96 \%$. After irradiation, the target drops into a lead container and is evacuated from the cyclotron vault on a remotely controlled trolley.

In cooperation with the Institute of Nuclear Chemistry and Technology and POLATOM, the HIL team has carried out research projects focused on medical applications of radioisotopes. The ALTECH grant included a search for alternative methods of technetium ${ }^{99 \mathrm{~m}} \mathrm{Tc}$ production using the socalled medical cyclotrons [3], and another joint project was the PET-SKAND grant, the aim of which was to obtain radiopharmaceuticals based on scandium radionuclides, in particular ${ }^{43} \mathrm{Sc},{ }^{44} \mathrm{Sc}$, and ${ }^{47} \mathrm{Sc}$, for PET [4-8].

Targets for these research made of ${ }^{100} \mathrm{Mo}$ for ${ }^{99 \mathrm{~m}} \mathrm{Tc}$ production and of $\mathrm{Ca}$ enriched isotopes for Sc isotopes production were produced by us.

The development of the methodology of Mo foils preparation starting from powder (the form in which the enriched isotopes are available) allowed obtaining foils with thicknesses down to $250 \mathrm{~nm}$ by mechanical reshaping (rolling) [9]. The foils were needed for studies on reaction cross-section performed before undertaking the regular irradiation of samples for isotope production. The production of ${ }^{99 \mathrm{~m}} \mathrm{Tc}$ was carried out using targets in a form of pellets formed by powder compacting.

The isotopic calcium targets applied for production of Sc isotopes were made directly from the calcium carbonate (the chemical form of available enriched isotopes) to avoid the loss of material during conversion into metal form. The important issue of target made of material which is an insulator (the case of carbonates) is the dissipation of the heat deposited by the beam in the target (see effect 
(a)
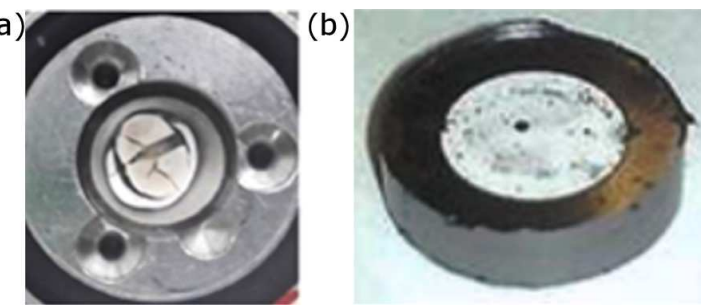

Fig. 3. (a) Pure $\mathrm{CaCO}_{3}$ target cracked after $2 \mathrm{~h}$ irradiation with $15 \mu \mathrm{A}$ proton beam of $16 \mathrm{MeV}$. (b) Pellet of $\mathrm{CaCO}_{3}$ placed in the graphite bed.

in Fig. 3a). To overcome this, a target with a small addition of graphite (having high heat transfer coefficient) had to be prepared or a small pellet of the target material had to be placed in the graphite bed with a bigger diameter (see Fig. 3b) [10, 11].

The HIL team has been working independently of the development of the manufacturing process and quality control of radiopharmaceuticals and candidates. The first to be developed and launched was the FDG manufacturing process. One of the results of the development work was to propose an improved procedure for testing residual organic solvents in radiopharmaceuticals [12] and to expand knowledge of metallic and radiometallic contaminants in the produced FDG. An interesting element of the research carried out was the identification of the main radioisotope contaminants that occurred due to side reactions with protons and secondary neutrons. Isotopes of $\mathrm{Co}, \mathrm{Mn}$, and $\mathrm{Ni}$ dominated but were easy to remove with chemical separation, resulting in a final product free from any radionuclidic impurities $[13,14]$.

However, our key role is to conduct research on new radiopharmaceuticals dedicated to ongoing biomedical projects, in cooperation with the Military Institute of Medicine, the Institute of Experimental and Clinical Medicine and the Warsaw University of Life Sciences. For this purpose, a regular, small-scale production of ${ }^{18}$ FMiso $\left({ }^{18} \mathrm{~F}\right.$-fluoromidazole) was developed and implemented for preclinical studies in small animals [15]. The radiopharmaceutical was used to assess changes in a tissue oxygenation status at various stages of tumor development and to compare it with biochemical methods. Incorporation of hypoxia information in clinical tumor assessment is important for clinical development of personalized, hypoxiabased therapies, which ultimately improve outcomes. More than 100 syntheses were performed, which, combined with the unique imaging capabilities of a small animal scanner located in the building of the Center for Biological and Chemical Sciences, of University of Warsaw, allowed a description of the model of the development of hypoxia in cancerous tissues [16].

Another fluorinated molecule, ${ }^{18} \mathrm{FHBG}$ (9-(4fluoro-3-hydroxy-methylbutyl)-guanine), was synthesized for imaging of gene-reporter system built-in selected stem cells, to visualize the progress of stem cell therapy of myocardial infarction damage in the heart. Over 30 runs have been carried out so far, significantly modifying the synthesis procedure and eliminating the problems described in other works related to the radiochemical purity of the final product. The method developed allowed a radiopharmaceutical with a purity of $>98.5 \%$ to be obtained, used for imaging of animal models with intracardial stem cell transplantation.

Another direction of development work was the use of the carbon-11 isotope for the labeling of endogenous molecules used in oncological diagnostics. A feasibility study of methionine, used in neurooncology [17], and acetates, used in the diagnosis of prostate cancer [18], was developed and conducted. Unfortunately, the complicated logistics caused by the short half-life of the isotope limits the possibility of using the developed methods in practice to centers where the scanner is located directly at the production center. Therefore, further efforts have been directed to metallic isotopes allowing the use of generators or isotopes with a longer half-life.

A complete "from target to image" project was the above-mentioned project for the production of ${ }^{44} \mathrm{Sc}$ and the synthesis of radiopharmaceuticals labeled with this isotope. For the isotope produced by RPRC, methods of isolation from the target material $[19,20]$ and the methodology of labeling peptides used in the diagnosis of neuroendocrine tumors (NET) have been developed. The developed procedure was automated using a system designed for flow-through scandium separation, connected to the Eckert-Ziegler automatic system for the synthesis of radiopharmaceuticals [5].

Another line of research was the development of novel radiopharmaceuticals labeled with metallic isotopes, available from generators gallium-68, copper-64. As a ligand for gallium-68, the flavonoid morin was selected, which showed high affinity for renal cancer cells in in vitro tests, and the synthesized compound was subjected to detailed chemical characterization [21]. In the case of copper, the macrocyclic ligand tetracarboxyphenylporphyrin (TCPP) was used, which can be a standalone ligand or can act as a bifunctional ligand (BFC) in the labeling of large biological molecules. A significant advantage of the developed method is its excellent kinetics, which allows labeling within a few minutes, compared to other methods that require marking processes lasting several hours [22]. A unique feature of the center is the possibility of conducting research on radiopharmaceuticals in the full cycle from designing the target through irradiation, isotope separation, radiopharmaceutical synthesis and imaging on small animals. The production equipment allows the preparation of any labeled compounds used in modern biomedical research. 


\section{Conclusions}

The constructed center is an example of the application of nuclear physics to raise the society's living standard. As one of the first producers of FDG, it contributed to the introduction of diagnostic examinations using positron emission tomography in Poland. The RPRC is used for daily, commercial production of FDG. It also allowed University of Warsaw to effectively engage in research on new radiopharmaceuticals. Within the research activity, we performed more than 100 irradiations of targets for research groups cooperating with us, producing several medical isotopes: ${ }^{99 \mathrm{~m}} \mathrm{Tc},{ }^{135} \mathrm{La},{ }^{43} \mathrm{Sc}$, and ${ }^{44}$ Sc. This production was dedicated to further radiochemical research.

The studies on the production of ${ }^{99 \mathrm{~m}} \mathrm{Tc}$ from ${ }^{100} \mathrm{Mo}$ and Sc isotopes from Ca also motivated the development of the target preparation technology. The technique developed for the production of thin Mo foils needed for studies of cross-section of ${ }^{100} \mathrm{Mo}(p, 2 n){ }^{99 \mathrm{~m}} \mathrm{Tc}$ reaction allowed the production of the Mo foil with thickness of $250 \mathrm{~nm}$.

The technique developed for the preparation of $\mathrm{Ca}$ targets used for $\mathrm{Sc}$ isotopes production allowed to overcome the problems of heat dissipation from targets made of insulators (carbonate powder inserted in the graphite - see Fig. 3).

The studies of ${ }^{100} \mathrm{Mo}(p, 2 n)^{99 \mathrm{~m}} \mathrm{Tc}$ reaction showed that measurements of thick target yield (TTY) allows the evaluation of the cross-section of the studied reaction [23].

The extension system of the PETtrace cyclotron will be used for medical radioisotope production in the future. We also plan to connect the PETtrace cyclotron with the U-200P heavy ion cyclotron (also installed at HIL). The radioisotopes produced in the RPRC would feed the ECR ion source of the U-200P cyclotron. This solution would allow the delivery of radioactive beams for research projects performed at HIL.

\section{Acknowledgments}

Some part of the RPRC research equipment was financed by the National Centre for Research and Development - Agreement No. PBS1/A9/2/2012, "Alternative Methods for the ${ }^{99 \mathrm{~m}} \mathrm{Tc}$ Production, ALTECH" and Agreement No. PBS3/A9/28/2015, "The Development of Methods for Production of New Radiopharmaceuticals Based on Sc Radionuclides Used in Positron Tomography (PET), PETSKAND".

\section{References}

[1] J. Choiński, J. Jastrzebski, K. Kilian, I. Mazur, P.J. Napiorkowski, A. Pękal, D. Szczepaniak, Nucl. Med. Rev. 15, C5 (2012).

[2] J. Choiński, Acta Phys. Pol. A 127, 1520 (2015).
[3] K. Szkliniarz, M. Sitarz, J. Jastrzębski et al., Mod. Phys. Lett. A 32, 1740012 (2017).

[4] K. Szkliniarz, M. Sitarz, R. Walczak et al., Appl. Radiat. Isot. 118, 182 (2016).

[5] K. Kilian, E. Cheda, M. Sitarz, K. Szkliniarz, J. Choiński, A. Stolarz, Molecules 23, 1787 (2018).

[6] M. Sitarz, K. Szkliniarz, J. Jastrzębski et al., Appl. Radiat. Isot. 142, 104 (2018).

[7] R. Walczak, W. Gawęda, J. Dudek, J. Choiński, A. Bilewicz, J. Radioanal. Nucl. Chem. 322, 249 (2019).

[8] W. Wojdowska, D. Pawlak, I. Cieszykowska et al., Nucl. Med. Rev. 22, 56 (2019).

[9] A. Stolarz, J.A. Kowalska, P. Jasiński, T. Janiak, J. Samorajczyk, J. Radioanal. Nucl. Chem. 305/3, 947 (2015).

[10] A. Stolarz, J.A. Kowalska, J. Jastrzębski, J. Choiński, M. Sitarz, K. Szkliniarz, A. Trzcińska, W. Zipper, AIP Conf. Proc. 1962, 020004 (2018).

[11] A. Stolarz, M. Sitarz, K. Szkliniarz, J. Choiński, J. Jastrzębski, A. Trzcińska, W. Zipper, EPJ Web Conf. 229, 06004 (2020).

[12] K. Kilian, A. Pekal, W. Szkutnik, K. Pyrzyńska, Microchem. J. 115, 95 (2014).

[13] K. Kilian, B. Chabecki, J. Kiec, A. Kunka, B. Panas, M. Wójcik, A. Pekal, Rep. Pract. Oncol. Radiother. 19, S22 (2014).

[14] K. Kilian, M. Pęgier, A. Pękal, K. Pyrzyńska, J. Radioanal. Nucl. Chem. 307, 1037 (2016).

[15] K. Kilian, Z. Rogulski, Ł. Cheda, A. Drzał, M. Gerszewska, M. Cudny, M. Elas, Nukleonika 61, 219 (2016).

[16] Ł. Kiraga, Ł. Cheda, B. Taciak et al., PLoS ONE 13, e0206706 (2018).

[17] K. Kilian, A. Pękal, J. Juszczyk, Nukleonika 61, 29 (2016).

[18] K. Kilian, A. Pękal, Acta Phys. Pol. A 127, 1475 (2015).

[19] K. Kilian, K. Pyrzyńska, M. Pęgier, Solvent Extr. Ion Exch. 35, 450 (2017).

[20] 20] M. Pęgier, K. Kilian, K. Pyrzyńska, Microchem. J. 137, 371 (2018).

[21] A. Sentkowska, K. Kilian, M. Kopeć, K. Pyrzyńska, Ł. Cheda, Appl. Organomet. Chem. 31, e3882 (2017).

[22] K. Kilian, M. Pęgier, K. Pyrzyńska, Spectrochim. Acta A 159, 123 (2016).

[23] M. Sitarz, J. Jastrzębski, F. Haddad, T. Matulewicz, K. Szkliniarz, W. Zipper, Instruments 3, 29 (2019). 